\section{Edycaçäa

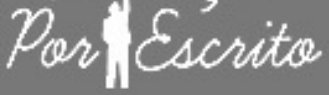

ARTIGO

\title{
Modelagem Matemática: uma prática realizada com professoras dos anos iniciais do Ensino Fundamental
}

\author{
Mathematical modelling: reporting an experince with teachers \\ from initial grades of Elementary School
}

\author{
Márcia Jussara Hepp Rehfeldta, Marli Teresinha Quartierib, leda Maria Giongo ${ }^{c}$
}

\section{Editores}

Maria Inês Côrte Vitoria PUCRS, RS, Brasil Pricila Kohls dos Santos PUCRS, RS, Brasil

\section{Equipe Editorial}

Rosa Maria Rigo

PUCRS, RS, Brasil

\section{RESUMO}

Este relato aborda as implicações de uma oficina desenvolvida no curso de formação continuada Tendências em Educação Matemática para os Anos Iniciais, promovido com um grupo de professoras dos anos iniciais. Especificamente, a temática explorada foi a Modelagem Matemática. Essa oficina foi realizada em dois encontros de duas horas cada um, e as práticas, planejadas e aplicadas nas turmas em que as docentes atuavam. A investigação inicial apontou que elas desconheciam a Modelagem Matemática, mas, após a oficina, passaram a utilizá-la no decorrer do ano. Ademais, enfatizaram que a oficina as motivou a utilizar essa metodologia por ser capaz de desenvolver a criatividade e a criticidade dos alunos.

Palavras-chave: Oficina; Anos iniciais; Modelagem matemática.

\section{ABSTRACT}

This report approaches proposals resulting from the continued education course Trends in Mathematics Education for the Initial Grades of Elementary School carried out with a group of teachers from that level. Specifically, the theme explored was Mathematical Modelling. The workshop was held in two meetings of two hours each, and the practices, planned and applied in the classes in which the teachers worked. The research pointed out that they were unaware of Mathematical Modeling, but after the workshop they began to use it throughout the year. In addition, they emphasized that the workshop motivated them to use this methodology for being able to develop the creativity and the criticality of the students.

Keywords: Work shop; Initial grades of Elementary School; Mathematical modelling.

a Doutora em Informática na Educação. Universidade do Vale do Taquari - Univates. Coordenadora Institucional da Pesquisa. Docente do Mestrado Profissional em Ensino de Ciências Exatas e do Mestrado em Ensino.

b Doutora em Educação. Professora do Centro Universitário UNIVATES, atuando nos cursos de graduação e de Pós-graduação (Mestrado em Ensino de Ciências Exatas e Mestrado em Ensino). Bolsista de Produtividade em Pesquisa 2 do CNPq.

c Doutora em Educação. Professora titular da Universidade do Vale do Taquari - Univates de Lajeado, RS, vinculada ao Centro de Ciências Exatas e Tecnológicas. Coordena o Grupo de Pesquisa Práticas, Ensino e Currículos (CNPq) e participa do Grupo Interinstitucional de Pesquisa em Educação Matemática e Sociedade (GIPEMS). 


\section{Introdução}

presente trabalho evidencia alguns resultados que emergiram durante a realização de uma oficina planejada para professoras dos anos iniciais do Ensino Fundamental no âmbito da Educação Matemática. Tal oficina constituiu uma das ações desenvolvidas na pesquisa "Ciências exatas - da escola básica ao Ensino Superior" e integrou o curso de formação continuada para docentes, denominado Tendências em Educação Matemática para os Anos Iniciais. Esse curso abordou várias temáticas, a saber: Jogos, Etnomatemática, Investigação Matemática e Modelagem Matemática.

Entretanto, o propósito deste relato é descrever apenas os encontros em que foi discutida a Modelagem Matemática. Por sua vez, os resultados advindos das problematizações serão debatidos no decorrer desses encontros. O curso completo, incluindo todas as temáticas, compôs-se de oito encontros presenciais e dois a distância. A oficina de Modelagem Matemática demandou dois encontros de quatro horas cada um, além de atividades realizadas a distância.

Como as ações se tratavam de uma investigação acerca das tendências em educação matemática, no final do semestre propôs-se às 18 participantes que descrevessem, em forma de relato, três práticas efetivadas em suas turmas e que tiveram como premissa o uso de uma das tendências problematizadas durante o curso. Apenas cinco exploraram atividades envolvendo a Modelagem Matemática.

Assim, o objetivo deste estudo é descrever as implicações da oficina desenvolvida com as 18 professoras dos anos iniciais na tendência da Modelagem Matemática. E, para embasar a narrativa, na próxima seção, são explicitados os aportes teóricos alusivos à temática e que sustentaram as discussões no curso.

\section{Pressupostos teóricos}

Os significados dos termos Modelo Matemático e Modelagem Matemática podem ser diferentes e mantêm uma relação estreita com as concepções, conhecimentos e valores de seus autores. Para Biembengut e Schimitt (2007), o modelo depende, antes de tudo, de como a pessoa percebe o meio, compreende, representa e procura comunicá-lo.

No que tange à modelagem, Machado Júnior (2005, p. 22), afirma que esta representa "um ambiente de aprendizagem no qual os alunos são convidados a indagar e/ou investigar, por meio de matemática, situações oriundas de outras áreas da realidade". De forma complementar, Barbosa $(2003,2006,2008)$ alude que, num ambiente de Modelagem Matemática, os alunos discutem, entre outros aspectos, o papel da Matemática na sociedade: 
O desenvolvimento de competências ou a aprendizagem de procedimentos e conceitos matemáticos, visto em outras perspectivas como propósitos primários, é considerado na perspectiva sócio-crítica como meio para gerar a discussão sobre o papel que os modelos matemáticos podem ter na sociedade (BARBOSA, 2008, p. 48).

Nessa perspectiva, a autora enfatiza ser recomendável que

[...] os alunos 'leiam' os modelos matemáticos de forma crítica, analisando como os resultados matemáticos dependem do lugar de onde eles são produzidos e como estes últimos são usados (Por quem são produzidos? Que resultados geram na sociedade? A quem beneficia? A quem prejudica? Etc.) (BARBOSA, 2008, p. 50).

Assim, Barbosa grifa que, por meio da Modelagem Matemática, é possível decidir e tomar decisões que favorecem a sociedade. Concorda-se que promover a Modelagem Matemática significa fazer pesquisa sobre um tema de interesse, além de estimular a criatividade e criticidade dos alunos. Ao resolver situações-problema, é necessário discernir e argumentar resultados que podem extrapolar o problema da vida real original (BIEMBENGUT e SCHIMITT, 2007).

Portanto, entende-se que a Modelagem Matemática representa uma metodologia para desenvolver determinada situação-problema real. Para tal, utilizam-se conceitos matemáticos que, por sua vez, auxiliam na tomada de decisões. À luz dos referenciais acima expostos, na seção a seguir, são descritos o contexto e as experiências realizadas com o grupo de professoras mencionados na introdução deste estudo.

\section{Metodologia do trabalho}

Neste item, abordam-se os diferentes momentos e as práticas realizadas com o grupo de professoras, a saber: a pesquisa inicial para avaliar os conhecimentos que elas possuíam em relação à Modelagem Matemática, a proposta inicial de Modelagem Matemática proporcionada pelo grupo de pesquisadores e, por fim, uma avaliação das atividades que as participantes propuseram aos seus alunos.

\section{Ação inicial: a pesquisa realizada com as participantes acerca dos conhecimentos prévios de Modelagem Matemática}

A primeira atividade realizada com o grupo de professoras consistiu em responder a um questionário contendo interrogações acerca de seus conhecimentos em Modelagem Matemática. A primeira indagava se elas já tinham 
ouvido falar de Modelagem Matemática. Das 18 participantes, 33\% responderam negativamente; outras 33 declararam que desconheciam, mas, possivelmente, haviam escutado comentários sobre o tema, porém com outra nomenclatura. As demais relataram não saber do que se tratava, embora já tivessem ouvido falar. A resposta da segunda questão corroborou a primeira, ou seja, $100 \%$ das docentes afirmaram que nunca haviam utilizado a Modelagem Matemática. À última indagação, "que aspectos/resultados didático-metodológicos você espera melhorar em sua prática pedagógica após problematizar a Modelagem Matemática nesta oficina?”, obtiveram-se as seguintes respostas:

- "Se possível, pretendo utilizar no meu dia a dia." (P11)

- "Primeiro conhecer o assunto e depois ver a sua aplicação." (P5)

- "Espero aprender e aplicar em sala para melhorar a aprendizagem dos meus alunos." (P8)

- "Espero aprendê-la, caso ainda não a tenha trabalhado com outro nome." (P9)

- "Espero experimentar essa prática para poder auxiliar os alunos na compreensão de conceitos matemáticos." (P10)

- "Espero compreender essa 'técnica' nesta aula para poder utilizá-la na prática diária de sala de aula.” (P11)

- "Espero aprender e poder aplicar com meus alunos." (P12)

Com essas respostas, foi possível compreender, por um lado, que o grupo de professoras pouco conhecia acerca de Modelagem Matemática. Por outro, elas estavam dispostas a aprendê-la, discuti-la e aplicá-la aos seus alunos.

\section{A primeira atividade de Modelagem Matemática: a problematização de uma receita de bolachas caseiras}

Após o preenchimento do questionário inicial aplicado anteriormente, foi oferecida a cada professora uma bolacha que serviu de mote para iniciar as discussões. Com isso, problematizou-se com o grupo a seguinte questão: "Que matemática poderia estar presente numa bolacha como esta?". Algumas das respostas expressas pelas participantes contemplaram o estudo das formas geométricas, a quantidade de confeitos na cobertura da bolacha e, de forma recorrente, a receita com seus custos.

Diante da insistência das professoras, disponibilizou-se a receita, testada anteriormente pela equipe de pesquisadoras. No Quadro 1, encontram-se os ingredientes e as quantidades para confeccionar as referidas bolachas.

1 As professoras são denominadas P1, P2 e assim sucessivamente para manter o anonimato. 
Quadro 1. Receita de bolacha de Natal

\begin{tabular}{|c|l|}
\hline Quantidade & \multicolumn{1}{c|}{ Ingrediente } \\
\hline 6 & Ovos \\
\hline 3 & Xícaras de açúcar \\
\hline $1 / 2$ & Xícara de leite \\
\hline $3 / 4$ & Xícara de manteiga \\
\hline 2 & Colheres de sal amoníaco \\
\hline 14 & Xícaras de farinha \\
\hline
\end{tabular}

Fonte: Pesquisadoras da oficina, 2015.

As bolachas, além de cozidas, estavam decoradas com confeitos coloridos, como mostra a Figura 1.

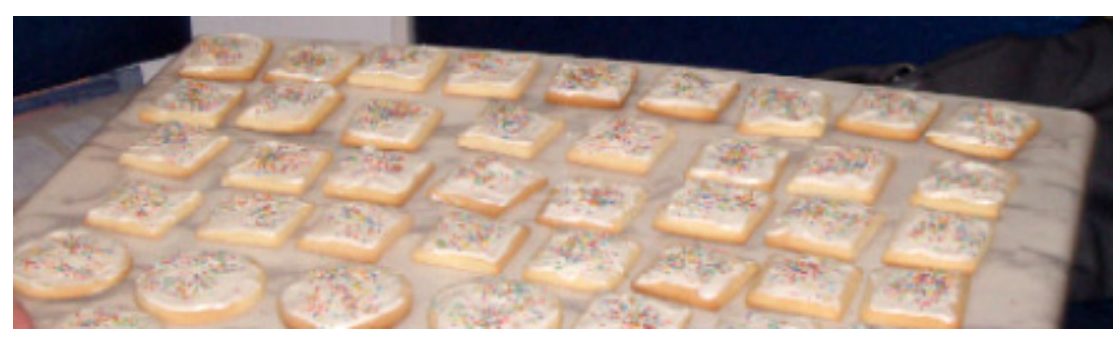

Fonte: Arquivo pessoal das pesquisadoras, 2015.

Figura 1. As bolachas confeccionadas pelas pesquisadoras

Assim, havia a necessidade de se contar com os ingredientes da cobertura. O Quadro 2 complementa essa receita.

Quadro 2. Cobertura das bolachas de Natal

\begin{tabular}{|c|l|}
\hline Quantidade & \multicolumn{1}{c|}{ Ingrediente } \\
\hline 2 & Claras batidas em neve \\
\hline 2 & Xícaras de açúcar \\
\hline 1 & Xícara de água \\
\hline 1 & Pote de $30 \mathrm{~g}$ de confeito \\
\hline
\end{tabular}

Fonte: Pesquisadoras da oficina, 2015. 
As professoras participantes da oficina questionaram se havia a possibilidade de se realizarem cálculos dos custos caso as xícaras e colheres fossem convertidas para quilos ou litros, haja vista os preços serem assim observados em supermercados. Cabe ressaltar que essas conversões foram realizadas pelo grupo de pesquisadoras, conforme é possível observar na Figura 2 e está disponibilizado no Quadro 3.

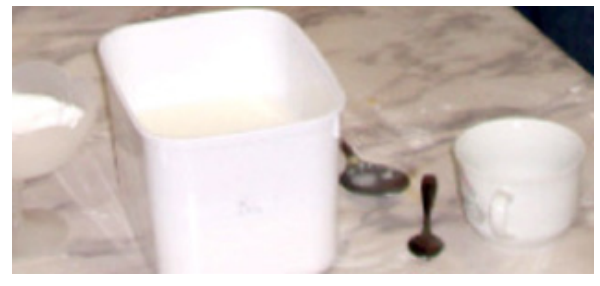

Fonte: Arquivo pessoal das pesquisadoras, 2015

Figura 2. Pesquisadoras realizando a conversão dos

ingredientes de xícaras para quilos ou litros

Quadro 3. Conversões das medidas da receita para medidas passíveis de mensuração de valor e encontradas no supermercado

\begin{tabular}{|l|c|}
\hline $\begin{array}{c}\text { Ingredientes encontrados } \\
\text { no supermercado }\end{array}$ & Equivalência \\
\hline $1 \mathrm{~kg}$ de açúcar & 6 xícaras \\
\hline 1 litro de leite & 6 xícaras \\
\hline $200 \mathrm{~g}$ de manteiga & 1,25 xícara \\
\hline $80 \mathrm{~g}$ de sal amoníaco & 10 colheres \\
\hline $1 \mathrm{~kg}$ de farinha & 9 xícaras \\
\hline
\end{tabular}

Fonte: Pesquisadoras da oficina, 2015.

Por fim, as professoras argumentaram que, se quisessem realizar qualquer cálculo, necessitavam dos valores dos ingredientes utilizados na receita. Partindo do pressuposto de que a Modelagem Matemática faz uso de dados reais, como sugerem McLone (1976), Barbosa (2001) e Bassanezi (2002), a equipe de pesquisadoras já havia investigado os preços dos ingredientes nas diversas formas (dúzia, meia dúzia ou ovos avulsos, por exemplo), encontradas num supermercado local. O Quadro 4 ilustra esses valores. 
Quadro 4. Custos dos ingredientes em um supermercado local

\begin{tabular}{|l|c|c|}
\hline \multirow{3}{*}{ Produto } & Unidade & Custo em R\$ \\
\hline \multirow{3}{*}{ Ovos } & Meia dúzia & 1,78 \\
\cline { 2 - 3 } & Dúzia & 3,45 \\
\cline { 2 - 3 } & Avulsos/dúzia & 3,15 \\
\hline \multirow{2}{*}{ Açúcar cristal } & $\mathrm{kg}$ & 1,95 \\
\hline Leite & $2 \mathrm{~kg}$ & 4,49 \\
\hline Manteiga & $5 \mathrm{~kg}$ & 10,99 \\
\hline \multirow{2}{*}{ Farinha de trigo } & $\mathrm{I}$ & 1,82 \\
\hline Sal amoníaco & $200 \mathrm{~g}$ & 3,98 \\
\hline Enfeite & $1 \mathrm{~kg}$ & 1,29 \\
\cline { 2 - 3 } & $5 \mathrm{~kg}$ & 5,48 \\
\hline
\end{tabular}

Fonte: Pesquisadoras da oficina com base nos preços do supermercado local, 2015.

Com todos os dados da receita disponíveis, algumas atividades de Modelagem Matemática foram propostas ao grupo de professoras. Seguem algumas destas:

1. Calcular a quantidade de ingredientes para dobrar, triplicar ou reduzir pela metade a receita.

2. Verificar:

a) Quantos quilos de açúcar são utilizados na receita original.

b) Com 1 litro de leite, quantas receitas de bolacha de Natal são possíveis de se fazer.

c) Com 1 pacote de $80 \mathrm{~g}$ de sal amoníaco, quantas receitas de bolacha de Natal são possíveis de ser realizadas.

3. Avaliar o que é mais barato: 2 meias dúzias ou 1 dúzia de ovos? Qual a diferença de valores?

4. Avaliar o que é mais barato proporcionalmente: $2 \mathrm{~kg}$ de açúcar ou $5 \mathrm{~kg}$ de açúcar? Qual a diferença de valores?

5. Avaliar o que é mais barato proporcionalmente: $1 \mathrm{~kg}$ de farinha ou $5 \mathrm{~kg}$ de farinha? Qual a diferença de valores?

6. Calcular o custo da receita.

7. Para produzir meia receita, foram gastos 30 minutos. Quantos minutos seriam necessários para produzir a receita inteira?

8. Quais as formas geométricas encontradas na base das bolachas? 
Cabe salientar que a discussão acerca da questão 7 foi oportuna e gerou muitas divergências. Uma destas foi: se o forno já estivesse aquecido, o tempo de cozimento seria menor? Em caso afirmativo, o tempo despendido não seria o dobro como parecia inicialmente. Outro aspecto que resultou em uma forte discussão foi o fato de um pacote de cinco quilos de farinha ser mais barato do que cinco pacotes de um quilo. Porém, nem sempre as famílias consomem o primeiro. Assim, uma quantidade significativa de farinha poderia ser desperdiçada ao final do mês.

Algumas dessas problematizações discutidas à luz de referenciais teóricos advindos das teorizações de Barbosa (2003, 2006, 2008) podem trazer contribuições no sentido de ilustrar o papel da Matemática na sociedade. Em outras palavras, poderia auxiliar as pessoas em processos decisórios, por exemplo, como comprar determinado tipo de alimento de forma mais barata.

No segundo encontro e ainda acerca da mesma tendência, cada equipe elaborou o roteiro de uma nova investigação de Modelagem Matemática que poderia ser desenvolvida com seus alunos. Os temas propostos pelas professoras foram canteiros de flores, casa de bonecas, jogo espirobol, ordenha e produção de leite, salada de frutas e forno de carvão. Durante o ano, essas propostas foram aplicadas nas turmas em que elas atuavam. Os resultados obtidos das avaliações dos trabalhos são descritos a seguir.

\section{Análise dos resultados obtidos pelas professoras dos anos iniciais}

A avaliação das práticas pedagógicas ocorreu em dezembro, quando as participantes expuseram suas experiências e entregaram, por escrito, um relato das atividades desenvolvidas. Das 18 professoras, cinco realizaram ações envolvendo Modelagem Matemática. Para a professora P4, "esse curso foi importante no sentido de que eu pude renovar e aprender algumas atividades para tornar as aulas mais atraentes, motivando assim meus alunos a participarem mais das mesmas". De forma semelhante, P5 mencionou:

Essas falas [referindo-se àquilo que os alunos de $\mathrm{P} 5$ disseram acerca das aulas] concluem que toda atividade realizada com alegria e prazer não se torna cansativa, pois fizemos muitas contas, pensamos muito, levamos oito aulas de matemática realizando esse projeto, mas concluí que não haveria melhor maneira de trabalhar contas com vírgula, quantidades, medidas, frações, de maneira mais gostosa e alegre.

Ao complementar, P2 afirmou que "quando a atividade de fazer a salada de frutas foi proposta, as duas turmas ficaram muito motivadas". 
Essas declarações levam a inferir que, além dos alunos, as professoras também se motivaram com as atividades diferenciadas. Cabe ainda destacar que, às vezes, em cursos de formação continuada, o objetivo dos docentes participantes é apenas um certificado, como mostra a narrativa da professora P4:

Quando fiz a inscrição para o curso, minha intenção era somar pontos para a avaliação anual dos professores estaduais e poder auxiliar e repassar "novidades" do ensino de Matemática para as colegas das séries iniciais. Minha surpresa e minha satisfação foram muito além desses objetivos. Aproveitei tudo nas minhas aulas de Matemática.

Ao observar as narrativas das professoras, é permitido afirmar que elas demonstraram interesse pela temática, assim como seus alunos. Ademais, o tempo dedicado às práticas revelou que elas realizaram as atividades com interesse e dedicação. Por fim, pode-se inferir que a metodologia da Modelagem Matemática se mostrou favorável para desenvolver a criatividade e a criticidade tanto dos alunos quanto das docentes.

\section{Considerações finais}

Durante as atividades realizadas, pôde-se observar o envolvimento de todas as professoras participantes. Além disso, elas colaboraram efetivamente no planejamento das atividades de modelagem, nas problematizações e na incorporação de novas sugestões.

Entende-se que as práticas de modelagem inspiraram ideias de pesquisa em sala de aula, como propõem Biembengut e Schimitt (2007). Ademais, instigaram o espírito investigativo e transformaram as professoras em questionadoras em oposição a simples respondentes. Conforme Bizzo (1998), a educação em áreas como Ciências deve oferecer aos estudantes a oportunidade de desenvolverem capacidades que possam despertar a inquietação diante do desconhecido, levando-os a adotar posturas críticas, a realizar julgamentos e a tomar decisões baseadas em critérios objetivos, fundamentados em conhecimentos compartilhados por uma comunidade escolarizada.

O fato é que as docentes participantes conseguiram propor atividades respondentes às questões relacionadas com o papel da Matemática na sociedade, mostrando, assim, que essa disciplina pode ter uma aplicabilidade. Cabe ressaltar que este estudo não se encerra aqui, e outras tendências da Educação Matemática, em particular, nos anos iniciais do Ensino Fundamental, devem ser analisadas e problematizadas por esta equipe de pesquisa. 


\section{Referências}

BARBOSA, J. C. Modelagem Matemática e os professores: a questão da formação. Bolema, Rio Claro, n. 15, p. 5-23, 2001. Disponível em: <http://www.ufrgs.br/espmat/disciplinas/funcoes_modelagem/modulo_I/modelagem_barbosa.pdf>. Acesso em: 28 ago. 2016.

. Modelagem Matemática e a perspectiva sócio-crítica. In: SEMINÁRIO INTERNACIONAL DE PESQUISA EM EDUCAÇÃO MATEMÁTICA, 2., 2003, Santos. Anais... São Paulo: SBEM, 2003. 1 CD-ROM.

. Mathematical modelling in classroom: a critical and discursive perspective. Zentralblatt für Didaktik der Mathematik, v. 38, n. 3, p. 293-301, 2006. 2008.

. As discussões paralelas no ambiente de aprendizagem Modelagem Matemática. Acta Scientiae, v.10, n.1, p. 47-57, jan./jun.

BASSANEZI, R. C. Ensino-aprendizagem com Modelagem Matemática: uma nova estratégia. São Paulo: Contexto, 2002.

BIEMBENGUT, M. S.; SCHIMITT, A. L. F. Mapeamento das pesquisas sobre Modelagem Matemática no cenário mundial: análise dos trabalhos apresentados no 14음 Grupo de Estudo do Comitê Internacional de Educação Matemática Study Group, 14 - ICMI. Dynamis (Blumenau), v. 13, p. 11-20, 2007.

BIZZO, N. Ciências: fácil ou difícil. São Paulo: Ática, 1998.

MACHADO JÚNIOR, A. G. Modelagem Matemática no ensino-aprendizagem: ação e resultados. 2005. 132 f. Dissertação (Mestrado) - Programa de Pós-Graduação em Educação em Ciências e Matemáticas, Núcleo Pedagógico de Apoio ao Desenvolvimento Científico, Universidade Federal do Pará, Belém, 2005. Disponível em: $<$ http://www.ufpa.br/npadc/gemm/documentos/docs/Doc_12.pdf $>$. Acesso em: 23 jan. 2013.

McLONE, R. R. Mathematical modelling: the art of applying mathematics, in Mathematical Modelling. London: Butterwords, 1976. SKOvSMOSE, O. Cenários de investigação. Bolema, Rio Claro, ano 13, n. 14, p. 66-91, 2000.

Recebido em: setembro/2017

Aceito em: outubro/2017

\section{Endereço para correspondência:}

Av. Avelino Talini, 171 - Universitário

95914-014 Lajeado, RS, Brasil

<mrehfeld@univates.br> 